\title{
MODELAGEM E SIMULAÇÃO DE VEÍCULOS AUTOMOTORES LEVES PARA ESTIMATIVA DO CONSUMO E EMISSÕES
}

\author{
João F. Amoroso de Oliveira ${ }^{1}$, Luiz Augusto Horta Nogueira ${ }^{1}$ e Daniel Padula Horta ${ }^{1}$ \\ ${ }^{1}$ Instituto de Engenharia Mecânica, IEM \\ Universidade Federal de Itajubá \\ E-mails: joaofranciscoamoros@gmail.com, lahortanog@gmail.com, \\ danielpmhorta@gmail.com
}

\section{RESUMO}

Esse trabalho apresenta a modelagem e simulação de veículos leves operando com diferentes sistemas de acionamento ("powertrains") em um ciclo de condução padronizado, visando estimar preliminarmente a demanda de energia e a emissão de gases de efeito estufa para cada caso. A modelagem do requerimento instantâneo de potência do veículo se baseou no equacionamento das forças estáticas e dinâmicas em seu movimento. Acoplando-se a esse modelo do veículo, os modelos dos powertrains para atender os requisitos de potência assumiram uma linearização ajustada do consumo com a potência, a partir do desempenho nas condições nominais, permitindo simular de forma expedita o comportamento energético do veículo ao percorrer um dado ciclo de condução. Foram modelados três powertrains: motor de combustão interna (MCI) (operando com gasolina E27 e etanol hidratado), sistemas de acionamento elétricos híbridos (VEH) (operando com gasolina E27 e etanol hidratado) e sistemas de acionamento elétrico com células de combustível (VEFC) utilizando hidrogênio produzido mediante reforma de etanol hidratado. A simulação de um veículo GM Onix Lt 1.4 flex percorrendo $12 \mathrm{~km}$ do ciclo de condução FTP-75 urbano, apresentou os seguintes consumos: MCI/gasolina: 12,24 km/1, MCI/etanol: 8,83 km/1, VEH/gasolina: 30,05 km/1, VEH/etanol: 22,61 km/1 e VEFC/etanol: $27,11 \mathrm{~km} / 1$. Esses resultados permitiram de forma imediata estimar as emissões de $\mathrm{CO} 2$ e se situam em níveis esperados, estimulando novos estudos, envolvendo outros veículos e outros ciclos de condução, bem como aperfeiçoamentos na abordagem desenvolvida.

\section{INTRODUÇÃO}

Em um cenário global, onde as preocupações ambientais e a transição para fontes de energia renováveis são recorrentes, há uma intensa discussão sobre qual será o futuro da mobilidade em relação as novas tecnologias que vêm sendo desenvolvidas. Nesse contexto o aumento da eficiência e a redução das emissões têm sido o foco principal da indústria automotiva, estimulando o desenvolvimento de tecnologias inovadoras. Diversos experimentos estão em andamento e uma quantidade importante de dados e resultados das novas tecnologias estão sendo disponibilizados. Sendo assim, os modelos de simulação tornam-se relevantes, possibilitando uma primeira avaliação de alternativas e otimização de procedimentos de testes.

O objetivo deste trabalho é explorar diferentes alternativas de powertrains, simulando computacionalmente o desempenho de alguns pares (veículo + powertrain) em um dado ciclo 
de condução para comparar desempenhos e emissões. Essa tarefa foi realizada em duas etapas: a modelagem dinâmica do veículo e a modelagem do comportamento dos sistemas que tracionam o veículo, também chamados de powertrains.

Simular o comportamento e estimar o consumo de energia de um automóvel em condições reais de uso não é uma novidade. De fato, existem diversas ferramentas que permitem a simulação através de modelos computacionais de veículos com diversos powertrains e diferentes fontes de energia. A maioria desses modelos citados adotam abordagens com o objetivo de simplificar essa análise usando aproximações matemáticas para representar os dados do ciclo de condução.

No próximo tópico se apresenta a estrutura da modelagem adotada e os dados do veículo de referência adotado para os estudos, apresentando-se a seguir os resultados da modelagem dinâmica do movimento do veículo e correspondentes requisitos de potência. Os sistemas de acionamento estudados são apresentados e modelados na sequência, apresentando-se finalmente os resultados da simulação, em termos do consumo de energia e emissões.

\section{METODOLOGIA DA MODELAGEM E SIMULAÇÃO}

O principal objetivo desse trabalho é estimar a demanda de energia de um veículo com um acionador genérico em um dado ciclo de condução. A primeira etapa para essa modelagem foi o equacionamento da dinâmica de movimento de um veículo. A partir dos dados de tempo e velocidade instantânea foi possível obter o dado de aceleração resultante do veículo. As perdas por atrito aerodinâmico, atrito por rolamento e atrito na transmissão foram consideradas no equacionamento.

Assumindo valores de coeficiente de arrasto, coeficiente de atrito de rolamento, área frontal do veículo, rendimentos e dados característicos de um motor foi possível identificar a demanda de energia exigida pelo veículo para um ciclo de condução. A partir dessa modelagem foi possível simular o sistema (veículo+powertrain) e estimar o consumo e as emissões em uma dada situação e principalmente comparar o desempenho de diferentes veículos e diferentes combustíveis. As etapas desse trabalho estão representadas no fluxograma abaixo e serão melhor explicadas nos próximos itens.

Fluxograma 1- Metodologia adotada

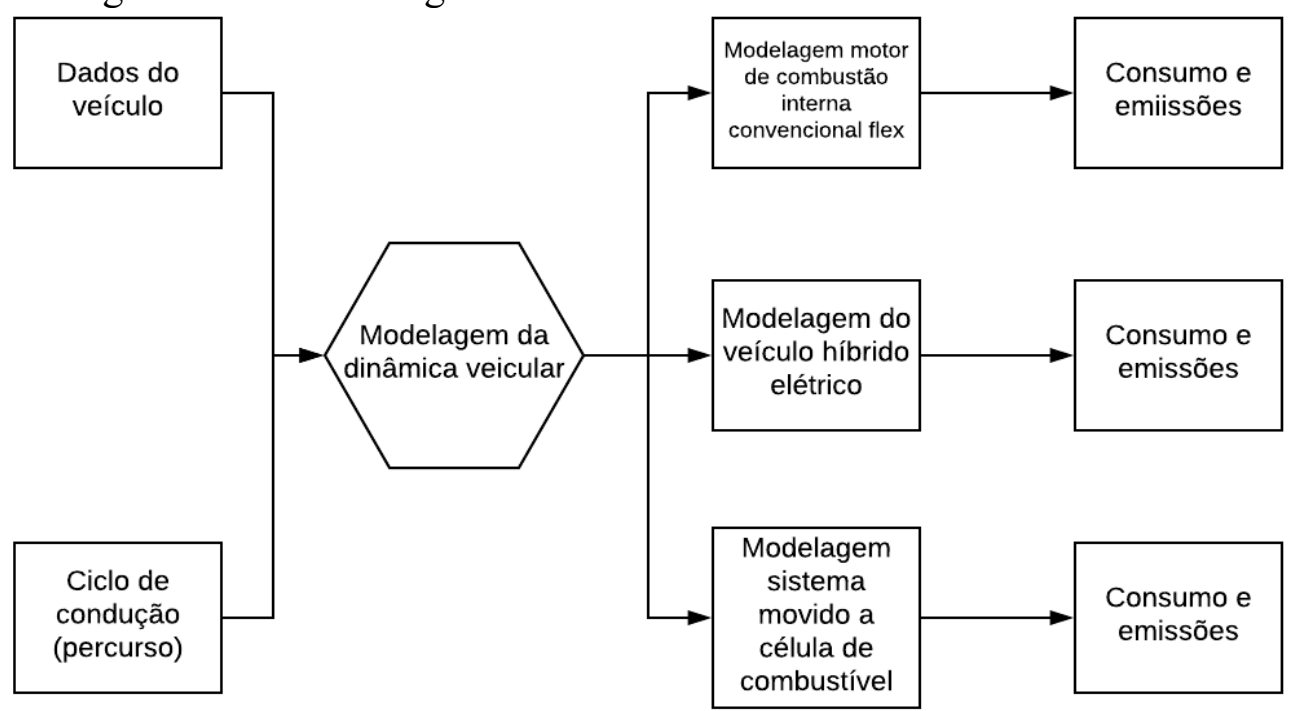

Fonte: Autores 
2.1 Veículo de referência estudado

O foco desta modelagem é a comparação de desempenho e emissões entre diferentes powertrains. Levando em consideração que o foco deste trabalho são os veículos automotores leves, os valores adotados para representar o modelo basearam-se no veículo GM Onix Lt 1.4 flex.[1] [2]

Para efeito de cálculos, foi considerada uma massa adicional para simular situação em que o carro transporta passageiros.

Tabela 1 - Valores adotados para o veículo modelo

\begin{tabular}{|l|c|c|c|}
\hline \multicolumn{1}{|c|}{ Parâmetro } & Símbolo & Unidade & Valor adotado \\
\hline Massa do veículo & $\mathrm{m}$ & $\mathrm{kg}$ & 1200 \\
\hline Área Frontal & $\mathrm{A}$ & $\mathrm{m}^{2}$ & 2,14 \\
\hline Coeficiente de arrasto & $C_{x}$ & - & 0,35 \\
\hline Rendimento de transmissão & $\eta_{m}$ & - & 0,94 \\
\hline
\end{tabular}

Fonte: Autores

\section{MODELAGEM DO PERCURSO}

Antes de se iniciar a modelagem dos powertrains, foi necessário a modelagem da dinâmica de movimento que um veículo apresenta quando este percorre um ciclo. Essa modelagem tem como objetivo obter o dado de demanda de energia que o sistema exige do powertrain.

Normalmente os diversos ciclos de condução disponíveis para estudos em condições de tráfego em estrada e cidade fornecem os dados de velocidade instantânea, permitindo obter os valores de forças e potências envolvidas nesse circuito, através das quais, por sua vez, é possível encontrar a energia necessária que o ciclo demanda. Para a análise desenvolvida no presente estudo, foi utilizada as duas etapas iniciais do ciclo de rodagem urbano FTP75 bastante utilizado na indústria automotiva e em estudos de emissões [3] [4]

Tempo de percurso: 1.369 segundos

Distância total: 11.981 metros

Velocidade Média: $31,5 \mathrm{~km} / \mathrm{h}$

Gráfico 1- Percurso FTP-75.

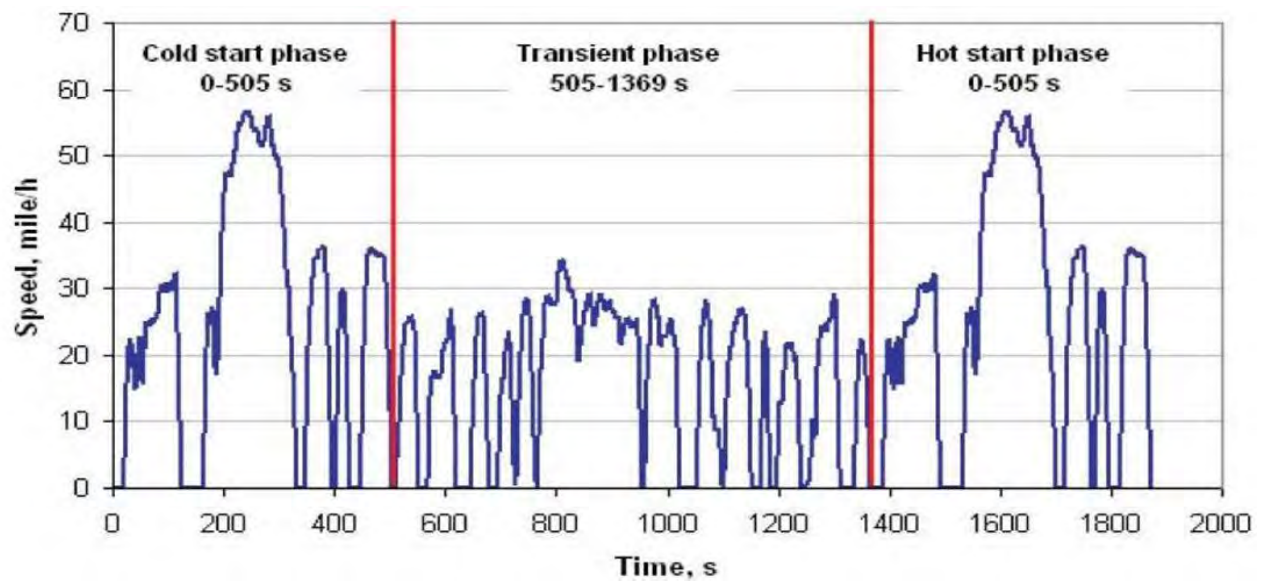

Fonte: (BARLOW,2009) 
Com os valores de velocidade ao longo do tempo foi possível obter a aceleração instantânea através da seguinte expressão:

Onde:

$$
a=\frac{V-V_{0}}{\Delta t}
$$

$a=$ Aceleração instantânea $\left(\mathrm{m} / \mathrm{s}^{2}\right)$

$V=$ Velocidade Instantânea $(\mathrm{m} / \mathrm{s})$

$V_{0}=$ Velocidade no instante anterior $(\mathrm{m} / \mathrm{s})$

$\Delta t=$ Variação de tempo entre $V$ e $V_{0}(\mathrm{~s})$

Após a obtenção aceleração instantânea, é possível obter o valor de força resultante ou líquida aplicada ao veículo através da expressão:

$$
F_{\text {resultante }}=m \cdot a
$$

Tabela 2 - Amostra da tomada de dados

\begin{tabular}{|c|c|c|c|}
\hline Tempo (s) & $\begin{array}{c}\text { Velocidade } \\
(\mathrm{m} / \mathrm{s})\end{array}$ & $\begin{array}{c}\text { Aceleração } \\
\left(\mathrm{m} / \mathrm{s}^{2}\right)\end{array}$ & $\begin{array}{c}\text { Força Resultante } \\
(\mathrm{N})\end{array}$ \\
\hline 25 & 6,39 & 1,16 & 1394,76 \\
\hline 26 & 7,55 & 0,18 & 214,58 \\
\hline 27 & 7,73 & 0,36 & 429,16 \\
\hline 28 & 8,09 & 1,16 & 1394,76 \\
\hline 29 & 9,25 & 0,45 & 536,45 \\
\hline 30 & 9,70 & 0,31 & 375,51 \\
\hline 31 & 10,01 & 0,04 & 53,64 \\
\hline 32 & 10,06 & $-0,18$ & $-214,58$ \\
\hline 33 & 9,88 & $-0,27$ & $-321,87$ \\
\hline 34 & 9,61 & $-0,27$ & $-321,87$ \\
\hline 35 & 9,34 & $-0,22$ & $-268,22$ \\
\hline 25 & 6,39 & 1,16 & 1394,76 \\
\hline 26 & 7,55 & 0,18 & 214,58 \\
\hline 27 & 7,73 & 0,36 & 429,16 \\
\hline
\end{tabular}

Fonte: Autores

A força resultante a cada instante resulta do balanço de forças no veículo, fornecida pela modelagem do movimento veicular. Nesse processo foi considerado que o veículo está sujeito a forças de arrasto, força de atrito de rolamento, força de frenagem, atrito na transmissão mecânica e força motora. A força resultante de uma possível inclinação de pista foi desconsiderada, assumindo que o ponto de partida e o ponto de parada final do veículo no ciclo estão sob a mesma elevação, sendo assim, o princípio da conservação da energia possibilita a desconsideração dessa parcela de força no sistema. [5] [6]

Assim, considerou-se a equação geral das forças que atuam no veículo:

$$
F_{\text {resultante }}=F_{\text {motora }}-F_{\text {atrito }}-F_{\text {arrasto }}-F_{\text {atritomecanico }}-F_{\text {freio }}
$$


Onde:

$F_{\text {motora }}=$ Força feita pelo motor $(\mathrm{N})$

$F_{\text {atrito }}=$ Força de atrito de rolamento $(\mathrm{N})$

$F_{\text {arrasto }}=$ Força de arrasto $(\mathrm{N})$

$F_{\text {atritomecanico }}=$ Perdas por atrito mecânico $(\mathrm{N})$

$F_{\text {freio }}=$ Força feita pelo freio $(\mathrm{N})$

As forças que compõe essa expressão são dadas pelas seguintes equações:

$$
F_{\text {atrito }}=\mu \cdot \mathrm{m} \cdot \mathrm{g}
$$

Onde:

$\mu=$ Coeficiente de atrito (adotado 0,01 para asfalto liso)

$\mathrm{m}=$ Massa do carro $(\mathrm{kg})$

$\mathrm{g}=$ Gravidade terrestre $\left(9,81 \mathrm{~m} / \mathrm{s}^{2}\right)$

$$
F_{\text {arrasto }}=\frac{1}{2} \cdot \rho_{\text {ar }} \cdot C_{x} \cdot A \cdot V^{2}
$$

Onde:

$\rho=$ Massa especifica do ar $\left(1,20 \mathrm{~kg} / \mathrm{m}^{3}\right)$

$\mathrm{Cx}=$ Coeficiente de arrasto

$\mathrm{A}=$ Área Frontal $\left(\mathrm{m}^{2}\right)$

$\mathrm{V}=$ Velocidade instantânea $(\mathrm{m} / \mathrm{s})$

$$
F_{\text {atritomecânico }}=F_{\text {motora }} \cdot\left(1-\eta_{m}\right)
$$

Onde:

$\eta_{m}=$ rendimento mecânico

Foi ainda adotada como hipótese que o veículo pode estar acelerando ou frenando. Dessa maneira, na equação geral (Eq. 3), quando a força resultante for maior que zero, temos apenas a força motora agindo e consequentemente força de frenagem não existe.

$$
F_{\text {resultante }}=F_{\text {motora }}-F_{\text {atrito }}-F_{\text {arrasto }}-F_{\text {atritomecanico }}
$$

Quando a força resultante é negativa, tem-se que o veículo está em um processo de redução de velocidade, porém isso pode corresponder a três situações. A primeira situação é que o freio está sendo acionado. A segunda situação é que apesar do powertrain aplicar uma força motora, as forças que vão no sentido oposto apresentam um somatório maior. E finalmente, a terceira hipótese é que o veículo possa estar apenas livre. Assim:

a) primeira situação: representa o momento que o freio está sendo acionado e não há força motora:

$$
F_{\text {resultante }}=-F_{\text {atrito }}-F_{\text {arrasto }}-F_{\text {freio }}
$$

b) segunda situação: a dinâmica veicular dever ser considerada igual a Eq.7, pois apesar da força resultante ser negativa o carro não está frenando, correspondendo à situação na qual 
apesar da força motora estar sendo aplicada, a soma das forças contrárias ao movimento é maior que a força fornecida pelo motor.

$$
-F_{\text {atrito }}-F_{\text {arrasto }}<F_{\text {resultante }}
$$

c) terceira condição: adotou-se um valor mínimo entre a soma da força resultante, força de atrito e força de arrasto (-200 N) para que se considere que o carro não está nem acelerando, nem frenando. Em outras palavras, no cálculo da primeira condição estabeleceu-se um valor mínimo para que a força de frenagem seja efetivamente considerada ou não exista. Tal conclusão resulta de uma análise do comportamento da velocidade do veículo observando que quando a velocidade diminui suavemente o veículo estaria em uma condição livre (sem aceleração nem frenagem) e quando a velocidade diminui de forma mais abrupta, o freio estaria sendo acionado. $\left(F_{\text {atrito }}+F_{\text {arrasto }}+F_{\text {resultante }}>-200(N)\right)$

$$
F_{\text {motora }}=F_{\text {freio }}=0
$$

A Tabela 3 apresenta valores representativos do estudo dinâmico efetuado. Dessa forma é possível caracterizar quando o veículo está frenando, utilizando o motor ou quando o carro está apenas livre na pista.

Tabela 3: Amostra de cálculo dinâmico de forças

\begin{tabular}{|c|c|c|c|c|c|r|r|r|}
\hline $\mathrm{T}(\mathrm{s})$ & $\begin{array}{c}\mathrm{V} \\
(\mathrm{m} / \mathrm{s})\end{array}$ & $\begin{array}{c}\text { Aceleração } \\
\left(\mathrm{m} / \mathrm{s}^{2}\right)\end{array}$ & $\begin{array}{c}\text { Força } \\
\text { Resultante } \\
(\mathrm{N})\end{array}$ & $\begin{array}{c}\text { Força } \\
\text { Frenagem } \\
(\mathrm{N})\end{array}$ & $\begin{array}{c}\text { Força } \\
\text { Atrito } \\
(\mathrm{N})\end{array}$ & $\begin{array}{c}\text { Forca de } \\
\text { Arrasto } \\
(\mathrm{N})\end{array}$ & $\begin{array}{c}\text { Força Atrito } \\
\text { Mecânico } \\
(\mathrm{N})\end{array}$ & $\begin{array}{c}\text { Força } \\
\text { Motora } \\
(\mathrm{N})\end{array}$ \\
\hline 28 & 8,09 & 1,16 & 429,16 & 0,00 & 117,72 & 25,74 & 22,85 & 380,89 \\
\hline 29 & 9,25 & 0,45 & 1394,76 & 0,00 & 117,72 & 26,97 & 36,63 & 610,48 \\
\hline 30 & 9,70 & 0,31 & 536,45 & 0,00 & 117,72 & 29,52 & 98,43 & 1640,43 \\
\hline 31 & 10,01 & 0,04 & 375,51 & 0,00 & 117,72 & 38,61 & 44,22 & 737,00 \\
\hline 32 & 10,06 & $-0,18$ & 53,64 & 0,00 & 117,72 & 42,44 & 34,19 & 569,86 \\
\hline 33 & 9,88 & $-0,27$ & $-214,58$ & 0,00 & 117,72 & 45,22 & 13,82 & 230,41 \\
\hline 34 & 9,61 & $-0,27$ & $-321,87$ & 0,00 & 117,72 & 45,62 & 0,00 & 0,00 \\
\hline 35 & 9,34 & $-0,22$ & $-321,87$ & 0,00 & 117,72 & 44,01 & 0,00 & 0,00 \\
\hline 36 & 9,12 & $-0,27$ & $-268,22$ & 0,00 & 117,72 & 41,66 & 0,00 & 0,00 \\
\hline 37 & 8,85 & $-1,25$ & $-321,87$ & 0,00 & 117,72 & 39,36 & 0,00 & 0,00 \\
\hline 38 & 7,60 & $-0,94$ & $-1502,05$ & 1349,00 & 117,72 & 37,50 & 0,00 & 0,00 \\
\hline
\end{tabular}

Fonte: Autores

Com os dados de força e velocidade instantânea, calcula-se os valores de potência motora e potência de frenagem instantâneas.

$$
P=F_{\text {resultante }} \cdot V
$$

Onde:

$\mathrm{P}=$ Potência instantânea (W)

$F_{\text {resultante }}=$ Força resultante $(\mathrm{N})$

$\mathrm{V}=$ Velocidade instantânea $(\mathrm{m} / \mathrm{s})$ 
Gráfico 2- Comportamento do veículo no percurso estudado

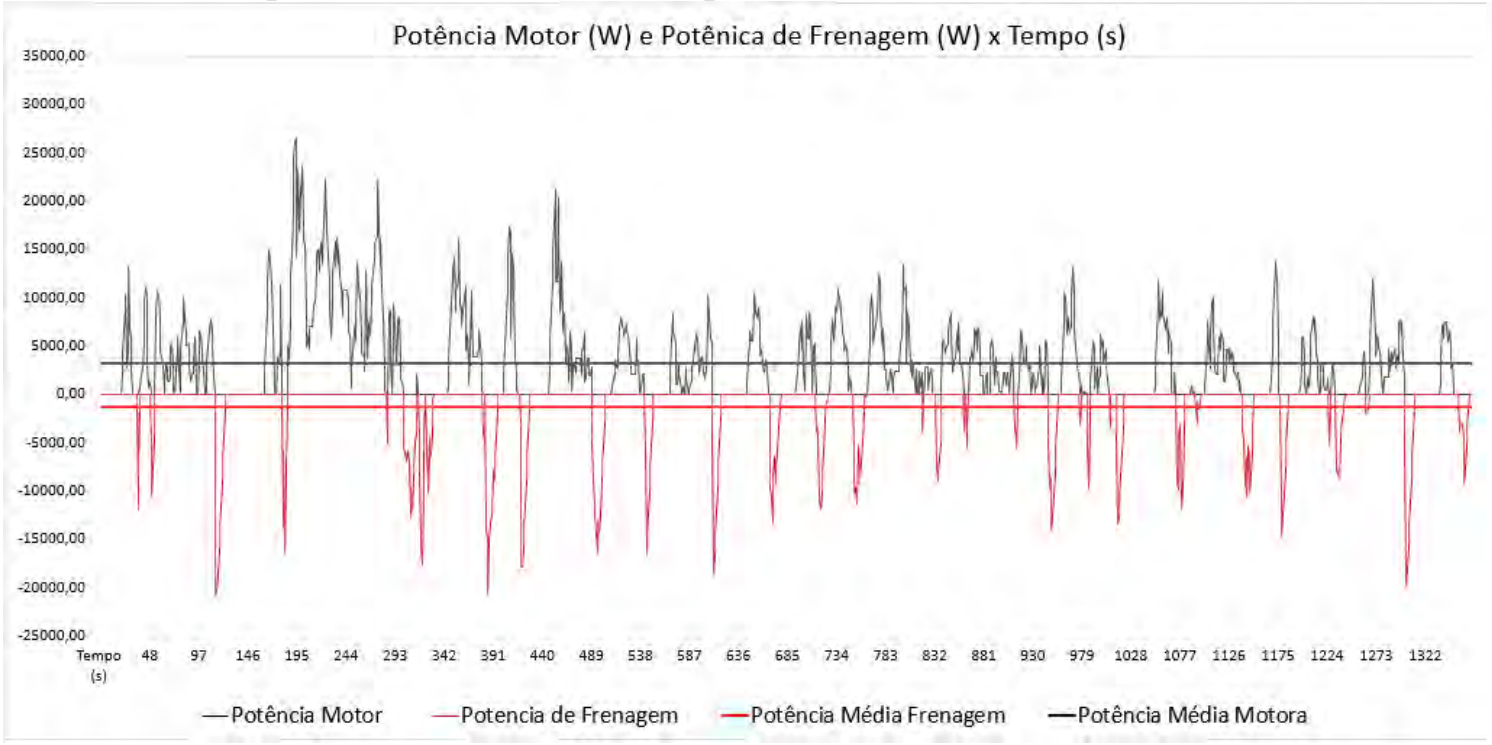

Fonte: Autores

Dessa forma foi possível obter os valores de potência motora e potência de frenagem, que utilizados em combinação com a modelagem dos powertrains fornecem o consumo e as emissões de cada par (veículo+powertrain). Para o veículo estudado os valores resultantes de potência média foram: a análise dinâmica do veículo teve como principal objetivo a obtenção dos valores médios da potência motora e da potência de frenagem. Esses dois dados servirão como informações de entrada na modelagem dos powertrains a serem analisados. A combinação dos dados citados acima com as modelagens de powertrains fornecerá o consumo e as emissões de cada veículo.

Potência média motora $=3224 \mathrm{~W}$

Potência média de frenagem $=-1294 \mathrm{~W}$

\section{MODELAGEM DOS SISTEMAS DE ACIONAMENTO}

4.1 Veículo a combustão interna (MCI)

Os veículos movidos a motores de combustão interna flexíveis são predominantes no cenário brasileiro e por isso foram tomados como referência para este trabalho. De fato, espera-se que as tecnologias inovadoras apresentem menor consumo e menores níveis de emissões de poluentes comparados a esse tipo de powertrain.

Para a modelagem de um motor de combustão interna aproximar-se o máximo possível da realidade foram assumidos alguns valores usuais para essa tecnologia, novamente referidos ao veículo de referência estudado no tópico anterior.

Os motores de combustão interna, quando utilizados para movimentar veículos, caracterizam-se por apresentar expressivas variações de carga, de acordo com as condições exigidas pelo veículo. A representação do comportamento desses motores é usualmente feita através dos campos de funcionamento com curvas de iso-rendimento e curvas de torque e potência em função da rotação. 
No presente estudo, considerando o caráter exploratório da modelagem desenvolvida e o fato de que em boa parte do tempo os veículos operam cerca à condição nominal, adotou-se uma linearização do consumo de combustível em relação a potência considerando dois pontos: o ponto onde se tem maior rendimento térmico, assumido como o ponto de máximo torque (normalmente fornecido nas fichas técnicas dos veículos) e o consumo em marcha lenta, ajustado a partir de dados de consumo real.

Desse modo, a equação utilizada para a linearização do consumo em relação a potência é a seguinte.

$$
\frac{C}{C_{o}}=A+(1-A) \cdot \frac{P}{P_{o}}
$$

Onde:

$C=$ Consumo instantâneo $(1 / \mathrm{h})$

$C_{o}=$ Consumo no ponto de máximo rendimento $(1 / \mathrm{h})$

$A=$ Coeficiente de mínimo consumo para funcionamento do sistema

$\mathrm{P}=$ Potência instantânea (W)

$P_{o}=$ Potênciano ponto de máximo rendimento $(\mathrm{W})$

O valor de A, associado ao consumo em marcha lenta (mínimo necessário para manter o motor funcionando), foi ajustado para obter na simulação os valores de consumo fornecidos pelo fabricante. Tipicamente, o consumo mínimo necessário para manter o motor funcionando, ou seja, a parcela A, situa-se entre 10 e $15 \%$ do consumo no ponto de máximo rendimento.

A potência no ponto ótimo é calculada a partir dos dados fornecidos na ficha técnica do motor. Para esse estudo, esses dados estão indicados na Tabela 4 [1].

Tabela 4 - Dados de torque e rotação da ficha técnica do Onix Lt - modelo 2017

\begin{tabular}{|c|c|c|c|}
\hline Combustível & Torque $(\mathrm{kgfm})$ & Rotação $(\mathrm{Rpm})$ & Potência $(\mathrm{W})$ \\
\hline Etanol & 13,9 & 4800 & 34234,81 \\
\hline Gasolina & 13 & 4800 & 3267,16 \\
\hline
\end{tabular}

Fonte: GENERAL MOTORS DO BRASIL LTDA, 2018

Os dados de potências no ponto ótimo foram calculados pela da seguinte maneira:

$$
P=\frac{g \cdot T \cdot n \cdot \pi}{60}
$$

Onde:

$T=$ Torque (kgfm)

$\mathrm{P}=$ Potência $(\mathrm{W})$

$\mathrm{g}=$ Gravidade da terrestre $\left(\mathrm{m} / \mathrm{s}^{2}\right)$

$\mathrm{n}=$ Rotação (rpm)

Para diferentes combustíveis ocorrem temos diferentes comportamentos. Para que esses comportamentos sejam mapeados foram adotados valores de poder calorífico para cada combustível. [7] 
Tabela 5 - Dados de poder calorífico do Etanol Hidratado e da Gasolina E27

\begin{tabular}{|l|c|}
\hline Combustível & Poder Calorífico $(\mathrm{kJ} / \mathrm{kg})$ \\
\hline Etanol hidratado & 22200 \\
\hline Gasolina E27 & 29500 \\
\hline
\end{tabular}

Fonte: BNDES, CGEE, FAO, CEPAL, 2008

Para o cálculo do consumo no ponto ótimo foi necessário assumir um valor de rendimento térmico ótimo do motor, adotando-se 33\% para ambos combustíveis na condição nominal, de máxima eficiência. Com os dados do motor combinados com a consideração anterior obteve-se o consumo em litros por hora na condição nominal, conforme a equação a seguir [8].

$$
C_{0}=\frac{P_{o}}{\eta_{t} \cdot P C I}
$$

Onde:

$\eta_{t}=$ Rendimento Térmico

PCI $=$ Poder Calorífico

A partir dos dados obtidos anteriormente e da equação 10, foi possível estimar o consumo do sistema de acionamento:

$$
C=C_{0}\left(A+(1-A) \frac{P}{P_{o}}\right)
$$

Com a linearização do consumo do veículo em função da potência fornecida é possível determinar a curva de comportamento do rendimento térmico de acordo com a equação 15 [8]. Os resultados para o motores a etanol hidratado e gasolina estão mostrados respectivamente nos Gráficos 3 e 4.

$$
\eta_{t}=\frac{P}{C \cdot P C I}
$$

Onde:

$\eta_{t}=$ Rendimento Térmico

PCI $=$ Poder Calorífico 
Gráfico 3: Linearização do consumo e comportamento do rendimento do motor (Etanol)

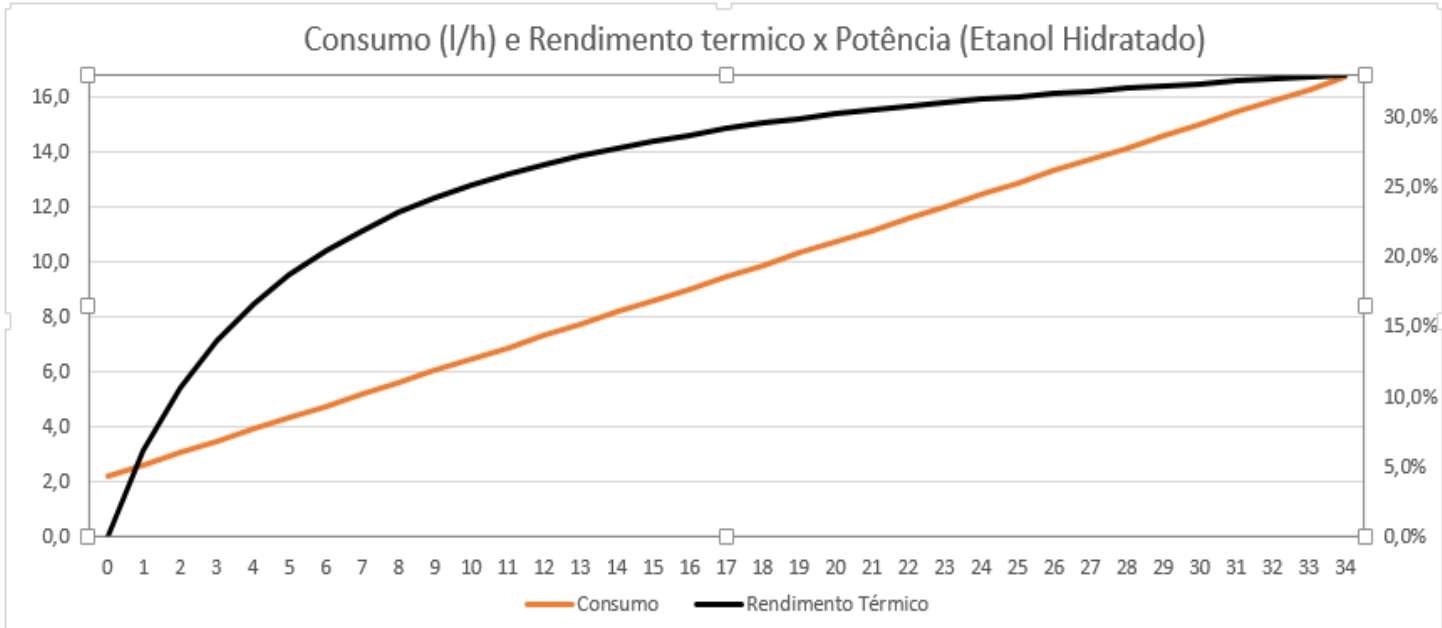

Fonte:Autores

Gráfico 4: Linearização do consumo e comportamento do rendimento (Gasolina E27)

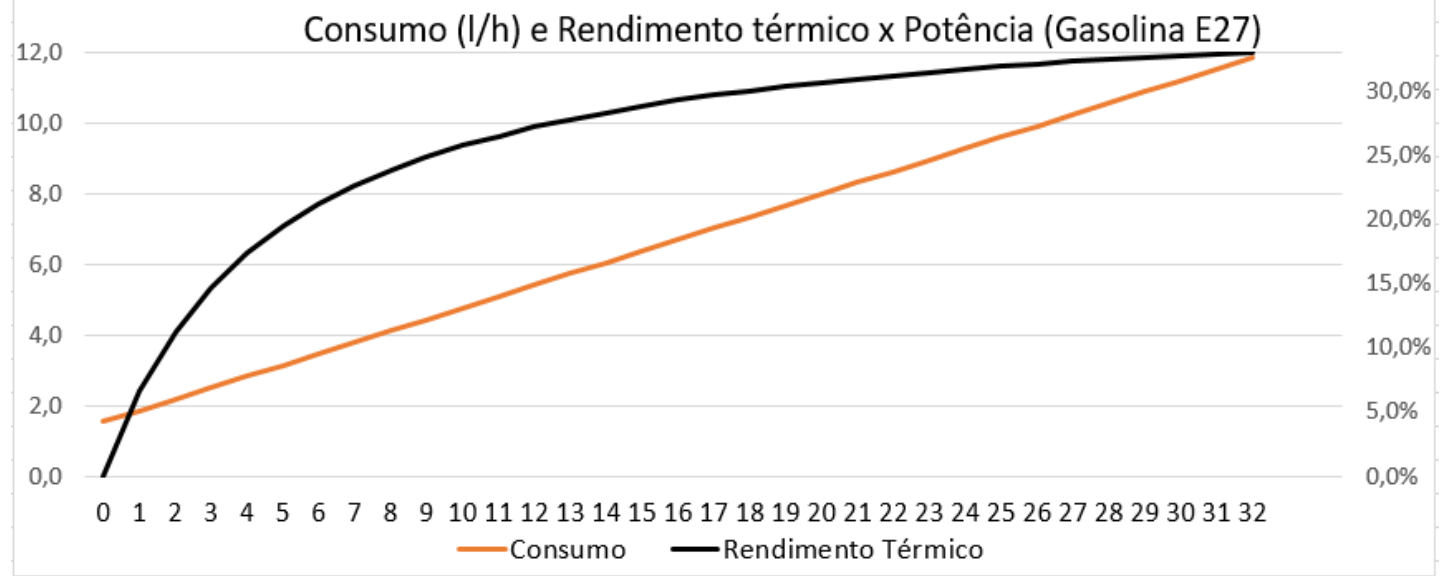

Fonte:Autores

A partir destes resultados, iterando o valor de potência média que o sistema demanda do motor em um dado percurso, foi possível descobrir o quanto de combustível foi consumido com as equações apresentadas anteriormente.

4.2 Veículos elétricos híbridos (VEH)

Os veículos elétrico híbridos consistem em um sistema caracterizado pela conversão da energia térmica do combustível em energia elétrica. Essa transformação é feita por um sistema que composto um motor a combustão, um gerador e um conjunto de baterias elétricas que por fim alimentam um motor elétrico que conduz o veículo. Existem graus de hibridização que caracterizam essa modalidade de powertrain, porém, como a análise que está sendo apresentada tem foco apenas no consumo de energia e emissões, não serão explorados os detalhes sobre o conjunto completo de um motor híbrido. Entretanto, para que tal consideração seja pertinente, foram adotados valores representativos para influência do uso de baterias, geradores e motores elétricos. 
Para a análise do consumo energético de um veículo elétrico híbrido considerou-se duas condições. A primeira condição levada em conta foi que, para o sistema de um veículo híbrido, o motor a combustão utilizado não estará ligado diretamente a tração do veículo. Em outras palavras, o motor a combustão terá a função de transformar a energia térmica do combustível em energia cinética que será convertida em energia elétrica em um gerador. Essa dinâmica de funcionamento faz com que a demanda de energia de um percurso não influencie em quais faixas de rendimento o motor irá trabalhar, e sim o quanto ele necessitará trabalhar para manter as bateiras carregadas o suficiente para completar o percurso. Portanto, o motor a combustão de um sistema híbrido não necessite trabalhar em diferentes condições de rotação e torque e consequentemente assumiu-se que o motor a combustão de um sistema híbrido trabalha em um valor próximo ao rendimento térmico ótimo apresentado por um motor de combustão interna convencional. [6] [9]

A segunda condição considerada foi que um sistema híbrido por trabalhar com conversão de energia térmica em energia elétrica viabiliza recuperação de energia dissipada com o acionamento dos freios. Esse tipo de conversão de energia nos freios se torna possível pela existência de sistemas chamados de freios regenerativos. A tecnologia mencionada permite que uma parcela da energia dissipada na frenagem possa ajudar a carregar as baterias. Para os sistemas de frenagem regenerativa existe um coeficiente de recuperação de energia que representa a porcentagem de energia que é reaproveitada de um processo de frenagem. [5] [10]

Considerando que existam perdas no gerador na transmissão e das baterias, adotou-se um rendimento térmico do sistema de $30 \%$. Esse valor é um pouco menor quando comparado ao rendimento térmico ideal de um veículo movido por um motor de combustão devido ao fato de existirem etapas na geração e armazenamento de energia elétrica. Para o coeficiente de aproveitamento de energia dissipada na frenagem foi adotado um valor de $50 \%$, levando em conta os valores mencionados nas referências citadas.

Para o cálculo da demanda média de potência que o sistema hibrido precisará produzir é feito um abate da energia demandada pelo ciclo subtraindo dela o valor de energia que o freio regenerativo consegue aproveitar. Essa situação é demonstrada pela equação abaixo

$$
P_{\text {média }}=P_{\text {motora }}-X P_{\text {frenagem }}
$$

Onde:

$P_{\text {média }}=$ Potência média produzida pelo sistema hibrido $(\mathrm{W})$

$P_{\text {motora }}=$ Potência Média motora exigida pelo ciclo (W)

$X=$ Coeficiente de aproveitamento de energia dissipada na frenagem

$P_{\text {frenagem }}=$ Potência média de frenagem $(\mathrm{W})$

Com a potência média exigida do sistema híbrido é possível encontrar o consumo médio que um veículo elétrico híbrido teria através da equação seguinte.

$$
C_{\text {médio }}=\frac{P_{\text {médio }}}{\eta_{t} \cdot P C I}
$$


Onde:

$C_{m e ́ d i o}=$ Consumo médio do veículo no ciclo de direção $(1 / \mathrm{s})$

$\eta_{t}=$ Rendimento térmico do sistema

$P C I=$ Poder calorífico do combustível $(\mathrm{kJ} / \mathrm{l})$

$P_{\text {médio }}=$ Potência média demandada pelo sistema $(\mathrm{kW})$

Com o dado de consumo médio do sistema em um dado ciclo, é possível encontrar o consumo total multiplicando consumo médio pelo o tempo do ciclo.

$$
C_{\text {total }}=\Delta T \cdot C_{\text {médio }}
$$

Onde:

$\Delta T=$ Tempo do percurso (segundos)

$C_{\text {total }}=$ Consumo total do percurso (litros)

Através do consumo total do percurso é possível calcular o consumo em quilômetros por litros que o veículo apresenta.

$$
C_{k m / l}=\frac{\Delta S}{C_{\text {total }}}
$$

Onde:

$C_{k m / l}=$ Consumo em quilômetros por litro $(\mathrm{km} / \mathrm{l})$

$\Delta S=$ Distância total do percurso $(\mathrm{km})$

4.3 Célula de combustível com reforma de etanol (VEFC com reforma de etanol)

Frente aos sistemas de acionamento anteriores, as células de combustível representam a tecnologia mais recente, mas com perspectivas interessantes devido à sua alta eficiência na conversão energética e as baixas emissões ao meio ambiente. As células de combustível convertem diretamente, sem combustão, a energia química em eletricidade, utilizando geralmente hidrogênio e produzindo energia elétrica e água.

Além de custo relativamente alto das células de combustível, o uso de hidrogênio traz dificuldades importantes, como o armazenamento. Quando no estado gasoso, o hidrogênio impõe o emprego de altas pressões, e quando no estado líquido é necessário estar em baixíssimas temperaturas. Uma das soluções para esse impasse é a produção de hidrogênio no veículo, mediante a reforma catalítica de etanol, uma alternativa promissora. No âmbito do presente estudo, assumiu-se um rendimento de $45 \%$ para o sistema reformador de etanol e célula de combustível. Considerou-se também que o processo de geração de energia elétrica tem um funcionamento continuo, ou seja, a demanda de energia ao longo do percurso é suprida instantaneamente pela célula de combustível, associada a um banco de baterias, como nos veículos híbridos. [5] [11].

Com os dados de potência média demandada pelo veículo e com o rendimento do sistema foi possível estipular o consumo e as emissões desse tipo de powertrain de forma simples, de modo similar ao adotado para um veículo híbrido. 


$$
C_{\text {médio }}=\frac{P_{\text {médio }}}{\eta_{s} \cdot P C I}
$$

Onde:

$C_{\text {médio }}=$ Consumo médio do veículo no ciclo de direção $(1 / \mathrm{s})$

$\eta_{s}=$ Rendimento total sistema

$P C I=$ Poder calorífico do etanol $(\mathrm{kJ} / \mathrm{l})$

$P_{\text {médio }}=$ Potência média demandada pelo sistema $(\mathrm{kW})$

Vale notar que agora o rendimento não é mais chamado de rendimento térmico devido ao fato de não envolver mais energia térmica, mas o potencial químico, ou energia livre de Gibbs, felizmente muito próximo do poder calorifico.

Com o valor do consumo médio do sistema foi possível encontrar o consumo total e consumo em quilômetros por litro através do da rotina demonstrada na modelagem do sistema elétrico híbrido pelas equações 16 e 17.

\section{ESTIMATIVA DAS EMISSÕES DE DIÓXIDO DE CARBONO}

O etanol e a gasolina são os dois combustíveis predominantemente usados em veículos leves no Brasil. Com a entrada do carro flex no mercado nacional, em 2003, os motoristas passaram a ter a opção de escolher qual desses dois combustíveis usariam para abastecer seus carros. Ambos os combustíveis desempenham muito bem a suas funções como fontes energéticas, mas por serem provenientes de fontes diferentes apresentam características particulares.

A queima de combustíveis fósseis é uma das principais causas do efeito estufa atualmente devido ao fato de que quando ocorre queima essa classe de combustível acaba-se tendo como resíduo o dióxido de carbono $\left(\mathrm{CO}_{2}\right)$. Esse tipo de gás é o principal causador do fenômeno citado acima pois ele, juntamente com outros gases que causam efeito estufa, acabam absorvendo a radiação emitida pela superfície da terra, funcionando assim como um isolante térmico. Para a modelagem apresentada o principal combustível que tem como característica ser proveniente de uma fonte de energia fóssil é a gasolina E27. Esse tipo de gasolina é predominante no mercado nacional quando se trata de veículos automotores leves e isso fez com que a análise das emissões provenientes dessa fonte de energia se tornasse pertinente.

O outro combustível em questão é o etanol hidratado. Esse tipo de combustível quando queimado em motores acaba não emitindo dióxido de carbono na atmosfera. Entretanto é válido considerar que, diferentemente de um combustível proveniente de fontes fosseis, o etanol hidratado para chegar aos postos de abastecimento precisa de um processo de produção que acaba emitindo dióxido de carbono na atmosfera também. Apesar do processo de produção do etanol contribuir para o efeito estufa, a diferença dos valores de emissões de $\mathrm{CO}_{2}$ causados pelo consumo de gasolina e etanol é notável. As emissões causadas pelo consumo de etanol estão por volta de $20 \%$ das emissões causadas pela queima de gasolina. Segue abaixo os valores de emissões em relação ao consumo de cada combustível. [12] 
Tabela 6: Emissão de dióxido de carbono por litro de combustível consumido

\begin{tabular}{|c|c|}
\hline Combustível & Taxa de Emissão $\left(\mathrm{kgCO}_{2} / \mathrm{l}\right)$ \\
\hline Gasolina E27 & 2,35 \\
\hline Etanol hidratado & 0,47 \\
\hline
\end{tabular}

Fonte: WANG,2014

Para o estudo comparativo, basta multiplicar o valor total de combustível consumido por cada tipo de powertrain (considerando qual combustível está sendo utilizado) pela taxa de emissão de dióxido de carbono para descobrir as emissões totais de cada situação.

\section{ESTUDO COMPARATIVO}

Após a modelagem descrita acima, foi possível obter os valores de consumo e emissões através do cruzamento de valores obtidos na modelagem da dinâmica veicular com a modelagens dos powertrains. Segue abaixo os valores obtidos.

Tabela 7 - Resultados finais

\begin{tabular}{|c|c|c|c|c|c|}
\hline & $\begin{array}{c}\text { MCI } \\
(\text { Gasolina } \\
\text { E27) }\end{array}$ & $\begin{array}{c}\text { MCI } \\
(\text { Etanol } \\
\text { Hidratado })\end{array}$ & $\begin{array}{c}\text { VEH } \\
\text { (Gasolina } \\
\text { E27) }\end{array}$ & $\begin{array}{c}\text { VEH } \\
\text { (Etanol } \\
\text { hidratado }\end{array}$ & $\begin{array}{c}\text { VEFC } \\
\text { (Etanol } \\
\text { hidratado })\end{array}$ \\
\hline $\begin{array}{c}\text { Emissões } \\
\left(\mathrm{kgCO}_{2}\right)\end{array}$ & 2,30 & 0,64 & 1,15 & 0,24 & 0,21 \\
\hline Consumo $(\mathrm{km} / \mathrm{l})$ & 12,24 & 8,83 & 30,05 & 22,61 & 27,11 \\
\hline
\end{tabular}

Fonte: Autor

Fundamentado nos resultados finais, foi possível estabelecer uma comparação entre os dados reais fornecidos em fichas técnicas com os dados coletados. O estudo comparativo entre valores reais e valores obtidos pela modelagem será feito entre os valores obtidos na modelagem do motor flex e os dados da ficha técnica de um veículo General Motors Onix Lt 1.4 flex. Essa decisão foi tomada tendo em vista que a maioria dos valores assumidos foram retirados da ficha desse modelo de veículo.

Outra observação pertinente é que o ciclo de condução FTP-75 é considerado um ciclo urbano, portando os valores de consumo em quilômetros por litros a serem comparados serão os valores das estimativas de consumo na cidade, como são citados nas fichas técnicas. [13]

Tabela 8 - Comparação dos resultados com valores reais

\begin{tabular}{|l|c|c|c|c|}
\hline \multirow{2}{*}{} & \multicolumn{2}{|l|}{ Onix LT - Ficha Técnica } & \multicolumn{2}{l|}{ Resultados Modelagem } \\
\cline { 2 - 5 } & Etanol & Gasolina & Etanol & Gasolina \\
\hline Consumo $(\mathrm{km} / \mathrm{l})$ & 8,6 & 12,5 & 8,83 & 12,24 \\
\hline
\end{tabular}

Fonte:Autores 
Gráfico 5 - Comparação entres os valores de emissões

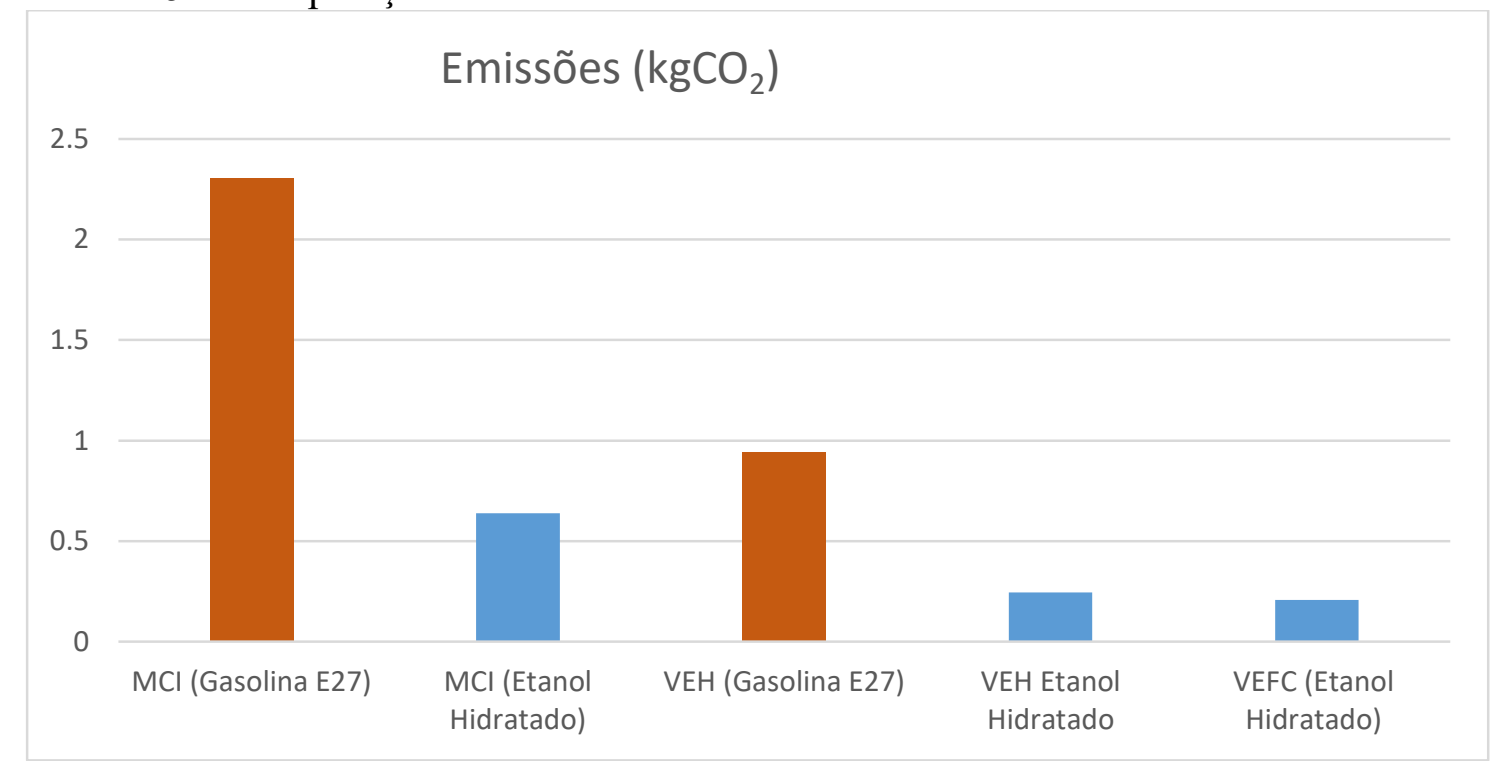

Fonte:Autores

Gráfico 6 - Comparação de consumo entre os powertrains

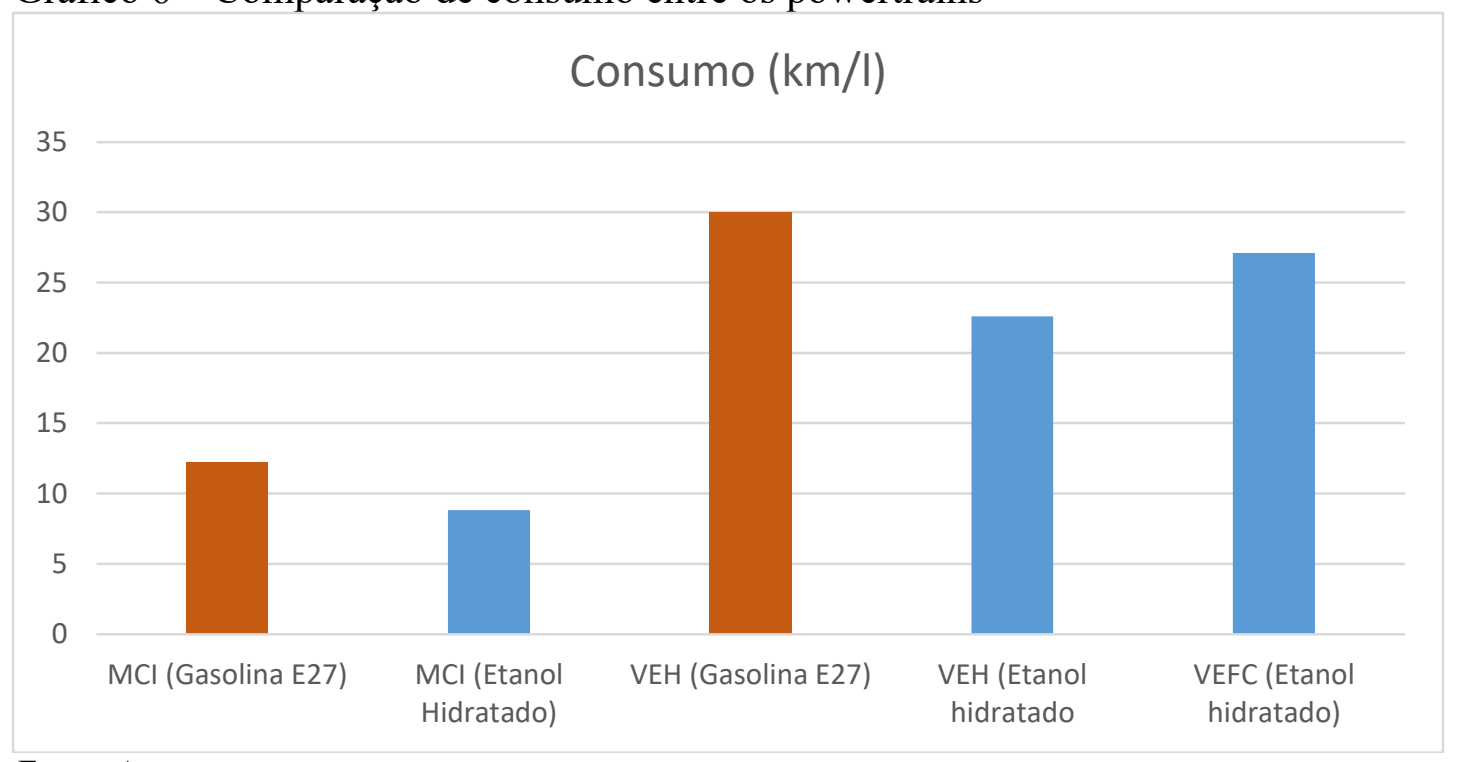

Fonte: Autores

\section{CONCLUSÃO}

Os resultados de consumo de combustível obtidos mediante a simulação de um veículo com diferentes configurações de sistemas de acionamento, utilizando a abordagem expedita desenvolvida neste trabalho, situaram-se em níveis esperados. De fato, a maior parte dos dados empregados foram retirados da ficha técnica do General Motors Onix LT modelo 2017, motor 1.4 flex, cujos valores de consumo estimados nesse estudo e indicados pelo fabricante apresentam valores comparáveis. 
Os resultados confirmam como a introdução de novas tecnologias podem induzir ganhos de eficiência relevantes, com benefícios econômicos e ambientais. Em comparação aos veículos com motores de combustão convencionais, os veículos elétricos híbridos e os veículos elétricos com células de combustível apresentaram reduções de consumo de combustível respectivamente de $61 \%$ e $67 \%$, assumindo em todos os casos o uso de etanol hidratado com o veículo desenvolvendo o ciclo urbano estudado. Em relação às emissões de gases importantes para as mudanças climáticas, também em comparação aos veículos com motores de combustão convencionais utilizando gasolina (E27), o uso de etanol hidratado em veículos com motores convencionais, com sistemas de acionamento elétricos híbridos e com células de combustível apresentaram reduções nas emissões de $\mathrm{CO}_{2}$ respectivamente de $72 \%, 90 \%$ e $91 \%$.

Embora os resultados apresentados nesse trabalho sejam preliminares, apresentam razoável aderência aos valores esperados e estimulam novos estudos, que devem envolver outros veículos e outros ciclos de condução, bem como aperfeiçoamentos na abordagem desenvolvida, especialmente visando um detalhamento maior do desempenho dos acionadores primários.

\section{REFERÊNCIAS}

[1] GENERAL MOTORS DO BRASIL LTDA. Ficha Técnica Onix LT 1.4 SPE/4. 2018. Disponível em: <http://www.chevrolet.com.br/carros/onix/ficha-tecnica.config\%3D14_spe4.h tml>. Data de Acesso: 17 de fev. 2018.

[2]DIAS, João. Transmissões. 2011. Material Didático (Especialização em Engenharia Automotiva) - Universidade Federal do Paraná, Paraná, 2011.

[3] BARLOW, T J et. al. A Reference Book of Driving Cycles for Use in the Measurement of Road Vehicle Emissions. 3. ed. Bracknell: HIS, 2009.

[4] PA - UNITED STATES ENVIRONMENTAL PROTECTION AGENCY. Dynamometer Drive Schedules. 2016. Disponível em: $<$ https://19january2017snapshot.epa.gov/vehicle-andfuel-emissions-testing/dynamometer-drive-schedules_html $>$. Data de Acesso: 20 de mar. 2018.

[5] SIMPSON, Andrew G. Parametric Modelling of Energy Consumption in Road Vehicles. 2005. Tese (PhD) - University of Queensland, Brisbane, 2005.

[6] HOLLANDA, Jayme Buarque. Engenharia dos Veículos Elétricos e Híbridos. 2011. Tradução Adaptada: Hybrid and Electric Vehicles, University of Colorado, 2010. Disponível em: < http://ecee.colorado.edu / ecen2060/materials/lecture_notes/2060_HEV_1.pdf $>$. Data de Acesso: 11 de abr. 2018.

[7] BNDES, CGEE, FAO, CEPAL. Bioetanol de cana de açúcar: bioenergia para o desenvolvimento sustentável. Banco Nacional de Desenvolvimento Econômico e Social, Rio de Janeiro, 2008

[8] Heywood, J. B. Internal Combustion Engine Fundamentals. 1988. Nova Iorque: McGraw Hill Education, 1988. 
[9] GUEZENNEC, Yann; SERRANI; Andrea; YURKOVICH, Steve. Modeling and Control of a Hybrid-Electric Vehicle for Drivability and Fuel Economy Improvements. 2008. Dissertação (Doutorado em Engenharia Mecânica) - Ohio State University, Ohio, 2008.

[10] Lakshmi, N Deepika et. al. Energy Efficient Electric Vehicle Using Regenerative Braking System. International Journal of Advance Research, Ideas and Innovations in Technology (IJARIIT), v.3, p. 55-58, abr. 2017.

[11] SILVA, C H F da Silva et. al. Produção de Hidrogênio Através de Reforma de Etanol. In: Congresso de Inovação Tecnológica em Energia Elétrica, 5., 2009. Belém. Anais do V CINVEL. Belém: ANEEL, 2009.

[12] Wang, M., Sabbisetti, R., Elgowainy, A., Dieffenthaler, D., Anjum, A., Sokolov, V., Zhang, Q., Farlene, D.M., Cronin, K., Robert, K., Ryman, A., Cai, H., Lu, P., 2014. GREET Model: The Greenhouse Gases, Regulated Emissions, and Energy Use in Transportation Model.

[13] INMETRO - INSTITUTO NACIONAL DE METROLOGIA QUALIDADE E TECNO LOGIA. Tabelas de Consumo/Eficiência Energética Veículos Automotores Leves. 2017. Disponível em: $<\mathrm{http}: / /$ www.inmetro.gov.br/consumidor/pbe/veiculos_leves_2017.pdf $>$. Data de Acesso: 10 de mar. 2018. 